\title{
DIVERSIDADE GENÉTICA DE ESPÉCIES DO GÊNERO Passiflora COM O USO DA ESTRATÉGIA WARD-MLM1
}

\author{
CLAUDIA LOUGON PAIVA ${ }^{2}$, ALEXANDRE PIO VIANA ${ }^{3}$, EILEEN AZEVEDO SANTOS ${ }^{4}$ \\ RAIMUNDO NONATO OLIVEIRA SILVA ${ }^{5}$, EDER JORGE DE OLIVEIRA ${ }^{6}$
}

RESUMO - O uso de espécies silvestres de maracujá tem resultado em progresso no melhoramento genético da cultura. No entanto, o uso dessas tem sido incipiente, devido à existência de poucas informações sobre a diversidade genética disponível. Tais atividades são essenciais para que os recursos genéticos do gênero Passiflora sejam utilizados com sucesso. Este trabalho objetivou quantificar a diversidade genética existente entre onze espécies do gênero Passiflora (Passiflora edulis, P. mucronata, P. setacea, P. pentagona, P. caerulea, P. gibertii, P. cincinnata, P. suberosa, P. micropetala, P. alata e P.coccinea). Foram utilizados descritores morfológicos qualitativos e quantitativos, sendo analisados conjuntamente por meio do procedimento WardMLM (Modified Location Model). Os acessos foram reunidos em cinco grandes grupos, sendo os caracteres relacionados às flores os que mais contribuíram para a diversidade genética dos acessos. O método de WardMLM possibilitou distinguir os subgêneros analisados, e houve uma clara separação entre as espécies. Vasta diversidade foi encontrada no gênero Passiflora, que pode ser explorada em programas de melhoramento do maracujazeiro.

Termos para indexação: caracterização, diversidade, recurso genético, Passiflora, Ward-MLM.

\section{GENETIC DIVERSITY OF THE GENUS Passiflora USING THE WARD-MLM STRATEGY}

\begin{abstract}
The use of wild species of Passion fruit has resulted in progress in the genetic improvement of this crop. However the use of these species have been incipient, due to little information about the genetic diversity. These activities are essential to genetic resources of the genus Passiflora to be used successfully. This research aimed quantify the genetic variability between eleven species of the genus Passiflora (Passiflora edulis, P. mucronata, P. setacea, P. pentagona, P. caerulea, P. gibertii, P. cincinnata, P. suberosa, P. micropetala, $P$. alata and P.coccinea). It was used quantitative and qualitative descriptors being analyzed in conjunction by the Ward-MLM procedure (Modified Location Model). This technique identified five groups based on pseudo-F and pseudo-t2 statistics. The characters related with floral part were the main contributors to genetic variability of the accessions. The Ward-MLM statistical procedure made possible the distinction of the subgenera analyzed, and there was a clear separation between the related species. A wide diversity was found in the genus Passiflora, that can be explored in passion fruit tree improvement programs. Index terms: characterization, genetic resource. diversity, Passiflora, Ward-MLM.
\end{abstract}

${ }^{1}$ (Trabalho 156-13). Recebido em: 05-04-2013. Aceito para publicação em: 13-02-2014.

${ }^{2}$ Bióloga, Doutoranda, Universidade Estadual do Norte Fluminense. E-mail: claudialougon@ gmail.tmail.com ${ }^{3}$ Eng. Agr., Dr. Professor Associado da Universidade Estadual do Norte Fluminense.E-mail: pirapora@uenf.br ${ }^{4}$ Bióloga, Doutora, Universidade Estadual do Norte Fluminense. E-mail: eileenazevedo@yahoo.com.br ${ }^{5}$ Biólogo, Doutorando, Universidade Estadual do Norte Fluminense. E-mail: j_raio@yahoo.com.br

${ }^{6}$ Eng.Agr., Dr. Pesquisador da Embrapa Mandioca e Fruticultura, Cruz das Almas, BA. E-mail: eder@cnpmf.embrapa.br 


\section{INTRODUÇÃO}

A fruticultura destaca-se no cenário econômico brasileiro, sendo o terceiro maior produtor mundial de frutas, com produtividade de cerca de 42 milhões de toneladas (ANUÁRIO BRASILEIRO DE FRUTICULTURA, 2012). Dentre as fruteiras, o maracujazeiro possui grande relevância devido a sua importância social e econômica para o País, sendo expressiva fonte de renda para os produtores e um mercado promissor para a indústria de sucos.

O Brasil é o maior produtor mundial de maracujá, com produção anual de aproximadamente 920.000 t, o que possibilita a geração de mais de 200 mil empregos diretos e indiretos (IBGE, 2011). Esta fruteira é cultivada em quase todo o território brasileiro, pelo fato de o País possuir condições edafoclimáticas favoráveis para o seu cultivo (PIRES et al., 2008). No entanto, para aumentar a produtividade dessa espécie, é necessário que cultivares mais produtivas, adaptadas a diferentes regiões do País e resistentes a doenças sejam introduzidas nos cultivos comerciais (MELETTI, 2011).

Assim, a inserção de espécies silvestres em programas de melhoramento é uma das maneiras para solucionar esses problemas, visto que essas podem conter genes de resistência a doenças e características agronômicas de interesse não encontradas no maracujazeiro cultivado (FALEIRO et al., 2004). Dessa forma, estudar a diversidade genética existente no gênero do maracujá com base em características agronômicas e de interesse para o melhoramento possibilita a identificação de genótipos superiores e contrastantes, indicando possíveis cruzamentos promissores.

Uma das maneiras para mensurar a diversidade genética é a utilização de descritores morfológicos. Caracteres qualitativos e quantitativos de fácil detecção, com alta herdabilidade e que sofram pouca variação ambiental, são utilizados a fim de diferenciar os acessos. Para quantificar a diversidade genética são utilizados diversos métodos de análises multivariadas. Dentre esses métodos, destaca-se o de Ward-MLM (Modified Location Model), proposto por Franco et al. (1998). Este método permite analisar variáveis quantitativas e variáveis qualitativas simultaneamente, acessando grande parte da informação disponível do germoplasma. Por intermédio dessa técnica é possível, ainda, definir o número ótimo de grupos e identificar, de forma fidedigna, a melhor probabilidade de cada acesso alocar-se em determinado grupo (GONÇALVES et al., 2009).
Dessa forma, o presente trabalho teve por finalidade estudar e quantificar a diversidade existente em espécies silvestres e comerciais de maracujazeiro, utilizando caracteres morfológicos qualitativos e quantitativos, empregando o método estatístico de Ward MLM.

\section{MATERIAL E MÉTODOS}

O estudo consistiu na caracterização de 70 acessos de onze espécies do gênero Passiflora: Passiflora edulis, P. mucronata, P. setacea, P. pentagona, $P$. caerulea, $P$. gibertii, $P$. cincinnata, P. suberosa, $P$. micropetala, $P$. alata e P.coccinea (Tabela 1). Este material foi obtido do Banco de Germoplasma da Embrapa Mandioca e Fruticultura e da coleção de Passifloras da Universidade Estadual do Norte Fluminense Darcy Ribeiro (UENF). O experimento foi conduzido em casa de vegetação, localizada na Unidade de Apoio à Pesquisa da (UENF), em delineamento inteiramente casualizado.

Os acessos foram caracterizados mediante descritores morfológicos propostos pelo Serviço Nacional de Proteção de Cultivares (SNPC), vinculado ao Ministério da Agricultura, Pecuária e Abastecimento (MAPA, 2008) a serem utilizados para proteção de cultivares de maracujazeiro. Foram utilizados 14 caracteres quantitativos (cinco no estádio vegetativo e nove no estádio reprodutivo) e dez qualitativos (dois no estádio vegetativo e oito no estádio reprodutivo), totalizando 24 caracteres. No ramo principal, 10 folhas e 10 flores foram utilizadas na caracterização, sendo esta iniciada na época de florescimento de cada genótipo. As avaliações foram realizadas no período de outubro de 2011 a junho de 2012.

Foram avaliadas as seguintes características quantitativas: diâmetro da flor (DF) a partir dos pontos extremos da flor; diâmetro da corona (DC), a partir dos pontos extremos dos filamentos da corona; comprimento dos filamentos da série externa da corona (TF), a partir da inserção no receptáculo da flor até o ápice; comprimento da pétala (CP), desde a inserção na flor até o ápice; largura da pétala (LP), na maior dimensão; comprimento da sépala (CS), desde a inserção na flor até o ápice; largura da sépala (LS), na maior dimensão; comprimento do androginóforo (TA), em toda a extensão que sustenta os órgãos sexuais; comprimento do pedúnculo floral (TP), a partir do receptáculo da flor até a inserção no caule; comprimento da bráctea (CB), desde a inserção no pedúnculo até o ápice; diâmetro do caule (DCA), na altura do segundo nó do eixo principal; comprimento 
da folha (CF), da base até o ápice; largura da folha (LF), na maior dimensão; comprimento do pecíolo foliar (CP), da inserção no caule até a inserção na folha. Todas as características quantitativas foram mensuradas com auxílio de paquímetro digital. Para os dados qualitativos, foram atribuídos códigos sequenciais numéricos de acordo com descritores para Passiflora (MAPA, 2008), observados os seguintes caracteres: coloração predominante no perianto (CPP), período predominante de antese (ANT), coloração predominante da corona (CPC), bandeamento nos filamentos mais longos da corona (BFLC), presença de número de anéis coloridos nos filamentos longos da corona (NACFLC), presença de glândulas nectaríferas nas brácteas (GB), forma dos filamentos da corona (FFC), forma do hipanto (FH).

A significância das variáveis quantitativas foi verificada por meio do teste-F. As variáveis qualitativas e quantitativas foram avaliadas simultaneamente, via procedimentos Ward-MLM (FRANCO et al., 1998) para compor os grupos de acessos, utilizando o método de agrupamento e o programa de matriz interativa do programa estatístico SAS (2003).

O agrupamento pelo método de Ward foi obtido pela matriz de distância, utilizando o algorítimo de Gower (1971) com variáveis contínuas e discretas. Com base nos critérios de pseudo-F e pseudo- $\mathrm{t}^{2}$, pelo método de Ward-MLM, foi fornecido o número ótimo de grupos para o conjunto de dados estudados. De acordo com o número ótimo de grupos, a classificação hierárquica foi obtida pelo método de Ward, que fornece os parâmetros necessários para implementar o passo final do modelo MLM (CROSSA; FRANCO, 2004). O diagrama que mostra as diferenças entre os grupos e a correlação das características com variáveis canônicas foi verificado pelo procedimento CANDISC do SAS (SAS INSTITUTE, 2003).

\section{RESULTADOS E DISCUSSÃO}

A partir da função logarítmica de verossimilhança, de acordo com os critérios do pseudo- $\mathrm{t}^{2}$ e do pseudo-F (SAS INSTITUTE, 2003), observou-se a formação de cinco grupos estabelecidos pela estratégia Ward-MLM (Figura 1). O número ideal de grupos foi verificado onde ocorreu maior incremento na função logarítmica, sendo verificado o maior valor absoluto de 97,94 no quinto grupo.

Com base nas características qualitativas e quantitativas, foi possível verificar ampla diversidade genética entre as espécies de Passiflora estudadas.
O grupo I alocou as espécies $P$. suberosa, $P$. micropetala e $P$. pentagona. Este agrupamento corresponde à classificação taxonômica atual, sendo o subgênero Decaloba (P. suberosa e P. micropetala) muito próximo filogeneticamente do subgênero Astrophea (P. pentagona) (MUSCHNER et al., 2003; MACDOUGAL; FEILLET, 2004). O grupo I caracterizou-se por possuir acessos com coloração branca na corona e no perianto, ausência de brácteas, ausência de bandeamento nos filamentos longos da corona e o período da antese pela manhã (Tabela 2). Além disso, os acessos que constituíram esse grupo possuem as menores médias para todos os descritores referentes à flor (Tabela 3 ). Características semelhantes foram encontradas por Krosnick e Freudenstein (2005) ao estudarem a monofilia e a homologia de caracteres florais do subgênero Decaloba. Esses autores verificaram que flores brancas e pequenas são típicas desse subgênero.

O grupo II foi formado pelas espécies $P$. mucronata e $P$. setacea, ambas pertencentes ao subgênero Passiflora. Antese noturna, flores brancas, filamentos longos da corona lisos e a forma do hipanto campanulada são algumas das características que este grupo compartilha (Tabela 2). Foram encontradas maiores médias ao analisar o tamanho do pedúnculo ( $88,5 \mathrm{~mm}$ ) e o comprimento da folha $(107,82 \mathrm{~mm})$, e o menor diâmetro do caule $(9,65$ $\mathrm{mm})$. Estudos revelam que $P$. mucronata é resistente à fusariose, e $P$. setacea possui um bom nível de resistência a doenças foliares, em especial ao vírus do endurecimento do fruto - Cowpea aphid-borne mosaic virus (CABMV) - e à morte precoce (FISHER et al., 2005; ATAIDE et al., 2012). Tendo em vista o uso dessas espécies como fonte de resistência a doenças que acometem o maracujazeiro (P.edulis), é de grande importância sua inserção em programas de melhoramento do maracujazeiro, por meio de cruzamentos interespecíficos, sendo possível obter genótipos resistentes.

O grupo III reuniu todos os acessos de $P$. cincinnata. Este grupo caracterizou-se por possuir flores com coloração roxa, corona com coloração azul-arroxeada e o formato ondulado dos filamentos longos da corona (Tabela 2). Neste grupo, foi encontrado maior média para o tamanho da corona $(102,71 \mathrm{~mm}) \mathrm{e}$, consequentemente, o maior tamanho de filamento $(47,00 \mathrm{~mm})$. O comprimento do pecíolo $(45,74 \mathrm{~mm})$ e o diâmetro do caule também obtiveram maiores $(21,96 \mathrm{~mm})$ médias se comparados com os outros grupos (Tabela 3). Além disso, este grupo apresentou o menor tamanho do androginóforo $(11,45 \mathrm{~mm})$ ao comparar com as espécies do subgênero Passiflora analisadas, sendo reduzida 
a distância entre o estigma em relação à corona, possibilitando a polinização por insetos menores (JUNQUEIRA et al., 2006).

O grupo IV foi constituído apenas por $P$. gibertii. Este grupo caracterizou-se por possuir flor branca, corona rosada, filamentos longos da corona lisos, formato aplanado do hipanto e antese no período vespertino (Tabela 2). O tamanho do androginóforo $(12,78 \mathrm{~mm})$, neste grupo, foi relativamente pequeno (Tabela 3). Foi constatado também que a média do diâmetro do caule $(14,73 \mathrm{~mm})$ possui uma semelhança quando comparada ao grupo V $(14,33$ $\mathrm{mm}$ ), onde o maracujazeiro-azedo está alocado. Considerando que P.gibertii é resistente tanto à morte prematura quanto à fusariose (RONCATO et al.,2004), estudos devem ser realizados a fim de verificar o potencial dessas espécies como porta-enxertos em espécies comerciais, visto que ambas possuem o caule com diâmetro semelhante, auxiliando assim no controle dessas doenças que muito acometem o maracujazeiro-azedo.

$\mathrm{O}$ grupo $\mathrm{V}$ foi representado pelas espécies P.edulis, P.caerulea, P.alata e P. coccinea. A presença de glândulas na bráctea e o formato campanulado foram características compartilhadas neste grupo (Tabela 2). Essas caracterizaram-se por possuírem as maiores médias do diâmetro da flor $(93,23 \mathrm{~mm})$, comprimento da pétala $(42,28 \mathrm{~mm})$, sépala $(42,50$ $\mathrm{mm}$ ) e bráctea $(28,39 \mathrm{~mm})$. Além disso, este grupo destacou-se por apresentar maior média no tamanho do androginóforo $(15,69 \mathrm{~mm})$. Essa média pode ter sido favorecida por alocar neste grupo $P$. coccinea, que possui o maior tamanho do androginóforo entre as espécies estudadas. Crochemore et al. (2003), ao realizarem a caracterização morfológica de onze espécies do gênero Passiflora, verificaram que P.edulis, P.caerulea e P.cocinea foram alocadas no mesmo grupo, semelhante aos resultados obtidos neste estudo.

As características quantitativas que mais contribuíram para quantificar a diversidade genética existente entre as espécies, com base na primeira variável canônica, foram: diâmetro do caule $(0,94)$; diâmetro da corona, $(0,88)$; tamanho do filamento $(0,88)$ e largura da sépala $(0,74)$. Para a segunda variável canônica, as variáveis que melhor se correlacionaram foram o comprimento da bráctea e o tamanho do androginóforo, ambas com valor de $0,53 \mathrm{~mm}$ (Tabela 3). Santos et al. (2011), ao quantificarem a diversidade genética entre P.foetida, P.sublanceolada e o híbrido correspondente, com base em caracteres morfológicos, verificaram que as variáveis que tiveram maior contribuição, conforme o método de Singh, foram o diâmetro da flor e o comprimento do pedúnculo.

As duas primeiras variáveis canônicas obtidas pelo método Ward-MLM explicaram $91,16 \%$ da variação total. Conforme Cruz e Carneiro (2006), caso as duas primeiras variáveis canônicas permitam estimativas acima de $80 \%$ da variação total, pode obter-se uma interpretação satisfatória da variabilidade entre os acessos, tal como ocorreu neste estudo, sendo possível a representação gráfica bidimensional (Figura 2). Sudré et al.(2010), utilizando o mesmo método estatístico para estimar a variabilidade genética entre acessos de Capsicum spp., obtiveram $90,5 \%$ da variação total também explicada pelas duas primeiras variáveis canônicas.

As distâncias entre os grupos, pela estratégia Ward-MLM, demonstrou uma amplitude de variação no valor de 366,16. A menor distância entre os grupos foi observada entre o grupo IV e o V, com valor estimado de 27,84, mostrando alta similaridade entre as espécies que compõem esse grupo. A maior dissimilaridade, com magnitude de 394,0 (Tabela 4), ocorreu entre o grupo I e o III. Essa diferença corrobora os estudos de filogenia molecular que os aloca em subgêneros distantes (MUSCHNER et al., 2003).

A proximidade de P.gibertii (grupo IV) das espécies do grupo $\mathrm{V}$ também foi encontrada ao quantificar a diversidade genética de onze espécies do gênero Passiflora por caracteres morfoagronômicos (CROCHEMORE et al., 2003). O fato de ambas as espécies pertencerem ao mesmo subgênero, conterem o mesmo número de cromossomos $(2 \mathrm{n}=18)$ (SOUZA et al., 2008) e compartilharem algumas características fenotípicas, pode estar associado a essa alta similaridade.

Várias são as diferenças entre o grupo I e o III que contribuíram para maior dissimilaridade entre esses grupos. O tamanho e a coloração das flores, em que espécies alocadas no grupo I possuem flores brancas de tamanho pequeno, e o grupo III caracterizou-se por apresentar flores grandes e roxas. Além disso, o número de cromossomos das espécies do grupo I $(2 n=24)$ difere-se dos demais grupos $(2 \mathrm{n}=18)$ (SOUZA et al., 2008).

Os descritores morfológicos utilizados foram capazes de diferenciar os subgêneros Decaloba e Passiflora, bem como separar de forma clara as espécies estudadas. Resultado semelhante foi obtido por Tangarife et al.(2009) ao realizarem a caracterização morfológica de 21 espécies do gênero Passiflora, incluindo três subgêneros. Este estudo permitiu distinguir os subgêneros de forma semelhante à classificação taxonômica, sendo as variáveis relacionadas à parte floral as que mais 
contribuíram para a separação das espécies. Viana et al.(2010) utilizaram onze descritores para avaliar seis espécies do gênero Passiflora e verificaram ampla variação morfológica inter e intraespecífica, obtendo clara separação das espécies.

Embora o gênero Passiflora possua um padrão característico da morfologia floral, é possível encontrar uma enorme plasticidade fenotípica, como no formato da folha, tamanho, forma e coloração das flores. Baseado nesta variedade, Killip (1938) subdividiu o gênero em 22 subgêneros. Esta classificação foi revista por Macdougal e Feuillet (2004) ao realizarem caracterização morfológica e ecológica, sendo reduzido a quatro subgêneros. Estudos de filogenia molecular (HANSEN et al., 2006; MUSCHNER et al.,2012) confirmaram a classificação do gênero Passiflora proposta por Macdougal e Feuillet (2004). Análises moleculares filogenéticas foram capazes de elucidar a monofilia do gênero Passiflora, revelando a proximidade entre os subgêneros Decaloba e Astrophea (MUSCHNER et al., 2012), o que corrobora os resultados obtidos neste estudo.

As análises geradas pelos descritores morfológicos demonstraram alta similaridade com a classificação botânica atualmente aceita para o gênero Passiflora (MACDOUGAL; FEUILLET,
2004). Este fato demonstra a consistência do método utilizado, podendo revelar o grau de parentesco entre as espécies. Isso pode estar relacionado ao fato de a maioria das características avaliadas estarem relacionadas com a morfologia floral e estas possuírem alta herdabilidade (KOBAYASHI et al., 2007).

A caracterização morfológica é uma etapa fundamental em programas de melhoramento de plantas, visto que possibilita conhecer o germoplasma e permite estimar a variabilidade genética, (MARIN et al., 2009). Este conhecimento possibilita ao melhorista explorar a diversidade, podendo realizar a introgressão de alelos favoráveis encontrados em espécies silvestres, como resistência a doenças, autocompatibilidade e redução do androginóforo, por intermédio de cruzamento interespecífico. Neste caso, deve-se ressaltar que, para que haja sucesso nos cruzamentos interespecíficos, o melhorista deve procurar acessos que estejam mais próximos geneticamente, sendo possivelmente compatíveis. Assim, as informações obtidas neste estudo poderão auxiliar na escolha de genitores, em programas de melhoramento do maracujazeiro que utilizem a hibridação interespecífica.grouping to optimize an objective function.

TABELA 1- Espécies do gênero Passiflora, subgênero, número de cromossomo, procedência, acesso e número de plantas analisadas.

\begin{tabular}{cccccc}
\hline Espécies & Subgênero & 2n & Procedência & Acesso & N $^{\circ}$ de planta \\
\hline P. alata & Passiflora & 18 & EMBRAPA & BGP 235 & 3 \\
& & & & BGP 016 & 4 \\
& & & & BGP 268 & 4 \\
P.cincinnata & Passiflora & 18 & EMBRAPA & BGP 274 & 4 \\
& & & & BGP 275 & 4 \\
& & & & BGP 290 & 2 \\
P.gibertii & Passiflora & \multirow{2}{*}{18} & EMBRAPA & BGP 008 & 4 \\
& & & & BGP 198 & 4 \\
& & & UENF & UENF & +4 \\
P.setacea & Passiflora & \multirow{2}{*}{18} & EMBRAPA & BGP 237 & 12 \\
& & & & BGP 238 & 1 \\
P.mucronata & Passiflora & 18 & UENF & UENF & 2 \\
& & & UENF & UENF-SF & 3 \\
P.pentagona & Astrophea & 24 & UENF & UENF & 1 \\
P.micropetala & Decaloba & 24 & UENF & UENF & 2 \\
P.caerulea & Passiflora & 18 & UENF & UENF & 2 \\
P. suberosa & Decaloba & 24 & UENF & UENF & 4 \\
P.coccinea & Passiflora & 18 & UENF & UENF & 3 \\
P.edulis & Passiflora & 18 & UENF & UENF & 4 \\
\hline
\end{tabular}




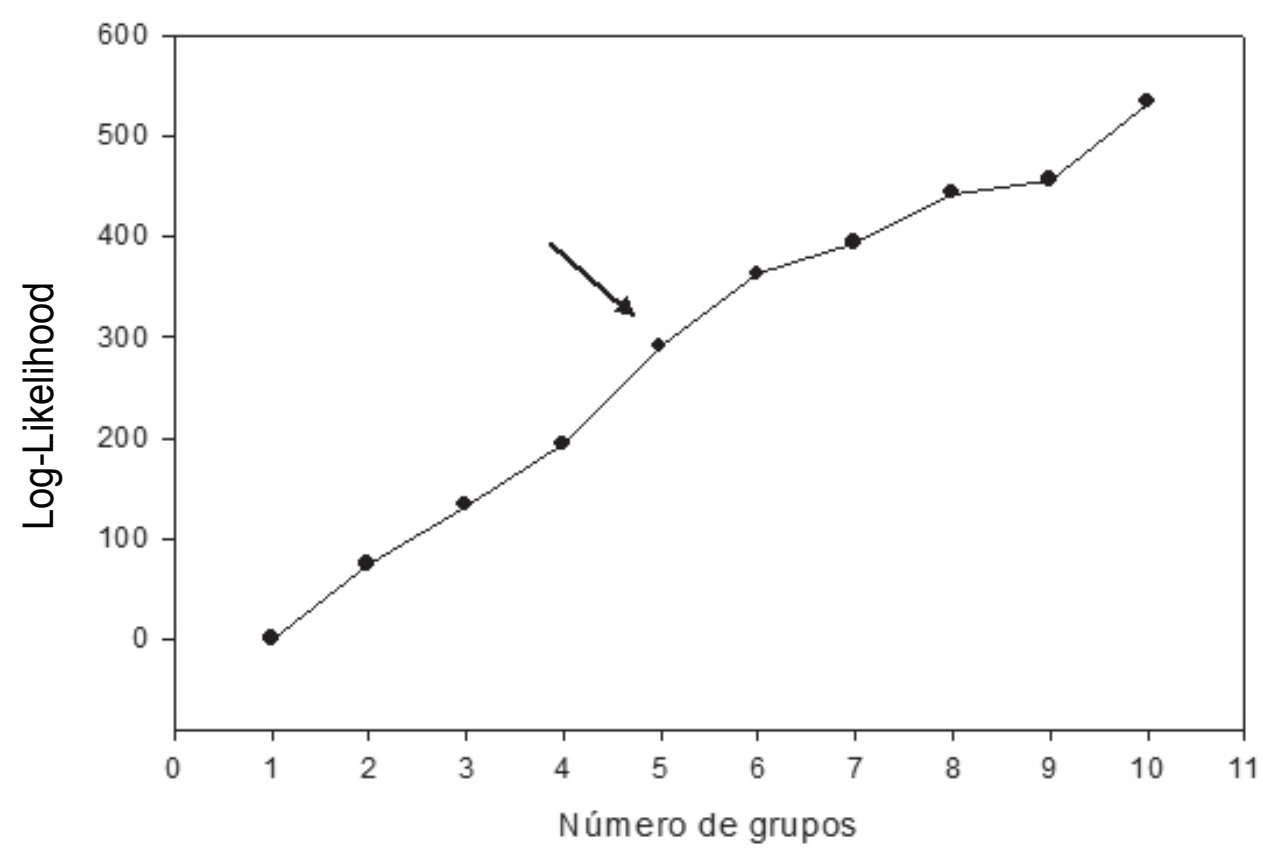

FIGURA 1- Função logarítmica de probabilidade (Log-Likelihood) com a formação de cinco grupos de agrupamento.

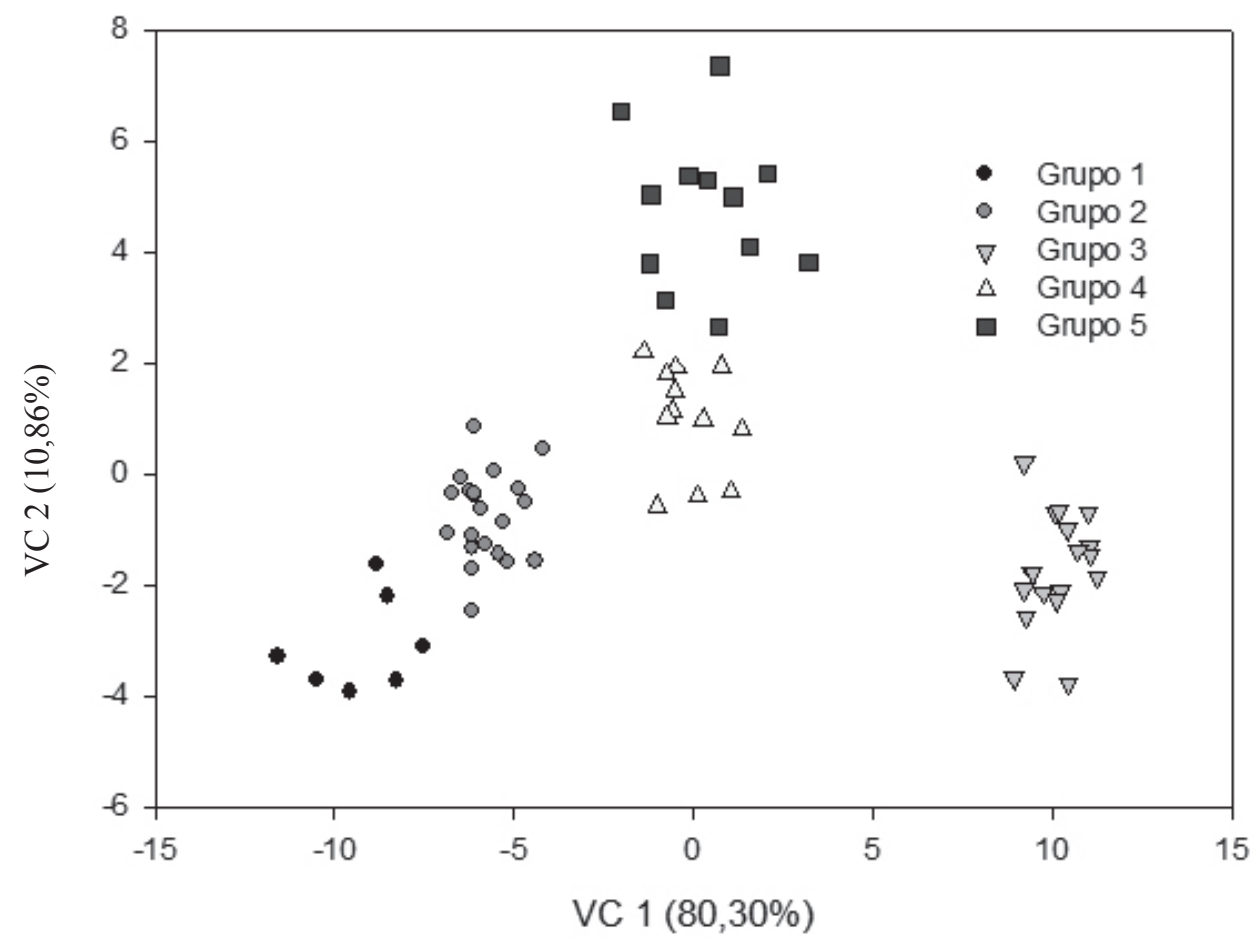

FIGURA 2- Dispersão gráfica das duas primeiras variáveis canônicas representando a formação de cinco grupos de espécies de Passiflora spp. Grupo I: P. suberosa, P. micropetala e P. pentagona; grupo II: $P$. mucronata e $P$. setacea; grupo III:P. cincinnata; grupo IV: $P$. gibertii; grupo V: P.edulis, P.caerulea, P.alata e P. coccinea. 
TABELA 2-Características qualitativas em cada grupo formado pela estratégia de Ward-MLM em espécies do gênero Passiflora.

\begin{tabular}{|c|c|c|c|c|c|}
\hline & \multicolumn{5}{|c|}{ Grupo (Acessos) } \\
\hline & GI (7) & $\mathrm{GII}(21)$ & GIII(18) & GIV(12) & $\mathrm{GV}(12)$ \\
\hline \multicolumn{6}{|l|}{ Formato do hipanto } \\
\hline Aplanado & 6 & - & - & 12 & - \\
\hline Campanulado & & 21 & 18 & - & 12 \\
\hline Cilíndrico & 1 & - & - & - & - \\
\hline \multicolumn{6}{|l|}{ Coloração predominante no perianto } \\
\hline Branca & 7 & 21 & - & 12 & 6 \\
\hline Rosada & - & - & - & - & - \\
\hline Vermelha & - & - & - & - & 6 \\
\hline Vermelho -arroxerada & - & - & - & - & - \\
\hline Roxa & - & - & 18 & - & - \\
\hline Azul-arroxeada & - & - & - & - & - \\
\hline Azul & - & - & - & - & - \\
\hline Coloração predominante na corona & - & - & - & - & - \\
\hline Branca & 7 & 21 & - & - & - \\
\hline Rosada & - & - & - & 12 & - \\
\hline Vermelha & - & - & - & - & - \\
\hline Vermelho-arroxerada & - & - & - & - & 6 \\
\hline Roxa & - & - & 8 & - & 4 \\
\hline Azul-arroxeada & - & - & 10 & - & - \\
\hline Azul & - & - & - & - & 2 \\
\hline \multicolumn{6}{|l|}{ Forma dos filamentos longos da corona } \\
\hline Liso & 5 & 21 & - & 12 & 8 \\
\hline $\begin{array}{l}\text { Ondulado } \\
\text { Bandeamento nos filamentos longos da } \\
\text { corona }\end{array}$ & 2 & - & 18 & - & 4 \\
\hline Ausente & 7 & 21 & - & - & 3 \\
\hline Presente & - & - & 18 & 12 & 9 \\
\hline \multicolumn{6}{|l|}{ Anéis coloridos nos filamentos longos } \\
\hline Ausente & 7 & 21 & - & - & 3 \\
\hline Presente & - & - & 18 & 12 & 9 \\
\hline \multicolumn{6}{|l|}{ Glândulas nas Brácteas } \\
\hline Ausente & 7 & 21 & - & 12 & - \\
\hline Presente & - & - & 18 & - & 12 \\
\hline \multicolumn{6}{|l|}{ Período de antese } \\
\hline Matutino & 7 & & 18 & & 8 \\
\hline Vespertino & & & & & 4 \\
\hline Noturno & & 21 & & & \\
\hline
\end{tabular}


TABELA 3- Médias das variáveis quantitativas para cada um dos cinco grupos formados pelo método Ward-MLM e as duas primeiras variáveis canônicas de Passiflora spp

\begin{tabular}{|c|c|c|c|c|c|c|c|}
\hline \multirow[b]{2}{*}{ Variáveis } & \multicolumn{5}{|c|}{ GRUPOS } & \multicolumn{2}{|c|}{ CAN } \\
\hline & G1 & G2 & G3 & G4 & G5 & CAN1 & CAN2 \\
\hline Comprimento da bráctea & 0,94 & 17,76 & 26,68 & 21,94 & 28,39 & 0,67 & 0,53 \\
\hline Comprimento da sépala & 15,18 & 37,25 & 41,54 & 34,89 & 42,50 & 0,51 & 0,41 \\
\hline Largura da sépala & 6,04 & 8,55 & 17,39 & 11,32 & 15,45 & 0,74 & 0,25 \\
\hline Comprimento da pétala & 8,12 & 32,32 & 41,26 & 27,60 & 42,28 & 0,60 & 0,41 \\
\hline Largura da pétala & 2,56 & 7,05 & 12,30 & 11,43 & 13,16 & 0,63 & 0,49 \\
\hline Diâmetro da flor & 31,94 & 80,45 & 89,54 & 72,40 & 93,26 & 0,51 & 0,43 \\
\hline Diâmetro da corona & 24,36 & 45,31 & 102,71 & 58,67 & 57,49 & 0,88 & $-0,10$ \\
\hline Tamanho do pedúnculo & 9,44 & 88,50 & 54,04 & 65,51 & 44,64 & $-0,10$ & 0,00 \\
\hline Tamanho do androginóforo & 7,71 & 13,93 & 11,45 & 12,78 & 15,69 & $-0,02$ & 0,53 \\
\hline Tamanho do filamento & 10,02 & 19,34 & 47,00 & 23,92 & 30,16 & 0,88 & 0,01 \\
\hline Comprimento da folha & 106,33 & 107,82 & 89,90 & 82,10 & 133,89 & $-0,26$ & 0,44 \\
\hline Largura da folha & 119,53 & 101,83 & 117,12 & 124,53 & 123,29 & 0,14 & 0,15 \\
\hline Comprimento do pecíolo & 21,92 & 41,59 & 45,74 & 37,60 & 34,80 & 0,36 & $-0,07$ \\
\hline Diâmetro do caule & 10,10 & 9,65 & 21,96 & 14,73 & 14,33 & 0,94 & $-0,08$ \\
\hline
\end{tabular}

Todas as variáveis foram medidas com paquímetro digital em milímetros (mm)

TABELA 4- Distância entre os grupos formados pelo método Ward-MLM para variáveis quantitativas e qualitativas.

\begin{tabular}{cccccc}
\hline GRUPOS & $\mathbf{1}$ & $\mathbf{2}$ & $\mathbf{3}$ & $\mathbf{4}$ & $\mathbf{5}$ \\
\hline 1 & 0 & 62,05 & 394,00 & 129,50 & 165,19 \\
2 & & 0 & 256,14 & 44,95 & 79,73 \\
3 & & & 0 & 120,27 & 138,78 \\
4 & & & & 0 & 27,84 \\
5 & & & & & 0 \\
\hline
\end{tabular}

\section{REFERÊNCIAS}

ANUÁRIO BRASILEIRO DE FRUTICULTURA. Santa Cruz do Sul: Editora Gazeta, 2012. p.112.

ATAIIDE, E.M.; OLIVEIRA, J.C.; RUGGIERO, C. Florescimento e frutificação do maracujazeiro silvestre Passiflora setacea D.C. Revista Brasileira de Fruticultura, Jaboticabal, v.34, n.2, p.377-381, 2012.

CROCHEMORE, M.L.; MOLINARI, H. B.; STENZEL, N. M. C. Caracterização agromorfológica do maracujazeiro (Passiflora spp.). Revista Brasileira de Fruticultura, Jaboticabal, v.25, n. 1, p.5-10, 2003.

CROSSA, J.; FRANCO, J. Statistical methods for classifying genotypes. Euphytica, Wageningen, v. 137, n.1, p.19-37, 2004.
CRUZ, C.D.; CARNEIRO, P.C.S. Modelos biométricos aplicados ao melhoramento genético. 2. ed.Viçosa: UFV, 2006. 585p.

FALEIRO, F.G.; JUNQUEIRA, N.T.V.; BELLON, G.; BORGES, T.A.; ANJOS, J.R.N.; PEIXOTO, J.R.; BRAGA, M.F.; SANTOS, D.G. Diversidade genética de espécies silvestres de maracujazeiro com resistência a múltiplas doenças com base em marcadores RAPD. Fitopatologia Brasileira, Brasília, v.29, p. 325, 2004.

FISCHER, I. H.; REZENDE, J. A. M.; FILHO, N. N.; SILVA, J. R. Ocorrência de Nectria haematococca em Maracujazais no Estado do Rio de Janeiro e Resistência de Passiflora mucronata ao Patógeno, Fitopatopatologia Brasileira, Brasília, v.30, n.6, p.671-671, 2005. 
FRANCO, J.; CROSSAJ.; VILLASENÕR, J.; TABA, S. Classifying genetic resources by categorical and continuous variables. Crop Science, Madison, v. 38, n.6, p.1688-1696, 1998.

GONÇALVES, L. S.; RODRIGUES, R.; DO AMARAL JÚNIOR, A T.; KARASAWA, M.; SUDRÉ, C. P. Heirloom tomato gene bank: assessing genetic divergence based on morphological, agronomic and molecular data using a Ward-modified location model. Genetics and Molecular Research, São Paulo, v. 8, n.1, p. 364-374, 2009.

GOWER, J.C. A general coefficient of similarity and some of its properties. Biometrics, Washington, v.27, p. 623-637, 1971.

HANSEN, A.K.; GILBERT, L.E.; SIMPSON, B.B.; DOWNIE, S.R.; CERVI, A.C.; JANSEN, R.K. Phylogenetic relationships and chromosome number evolution in Passiflora. Systematic Botany, Kent, v.31, n.1, p.138-150, 2006.

IBGE. Censo Agropecuario 2011: lavoura permanente e temporária. Disponível em: $<$ http://www.sidra.ibge.gov.br/bda/tabela/listabl. asp? $\mathrm{z}=\mathrm{t} \& \mathrm{o}=11 \& \mathrm{i}=\mathrm{P} \& \mathrm{c}=1181>$. Acesso em: 28 jan 2013.

JUNQUEIRA, N.T.V.; LAGE, D.A.C.; BRAGA, M.D.; PEIXOTO, J.R.; BORGES, T.A.; ANDRADE, S.R.M. Reação a doenças e produtividade de um clone de maracujazeiro-azedo propagado por estaquia e enxertia em estacas herbáceas de passiflora silvestre. Revista Brasileira de Fruticultura, Jaboticabal, v. 28, n. 1, p. 97-100, 2006.

KILliP, E. P. The American species of Passifloraceae. Chicago: Field Museum of Natural History, 1938, 613p. (Botanical Series, 19)

KOBAYASHI, K.; HORISAKI, A.; NIIKURA, S.; OHSAWA,R. Diallel analysis of floral morphology in radish (Raphanus sativus L.). Euphytica, Wageningen, v.158, p.153-165, 2007.

KROSNICK, S. E.; FREUDENSTEIN, J. V. Monophyly and Floral Character Homology of Old World Passiflora ( Subgenus Decaloba : Supersection Disemma ) Systematic Botany, Kent, v.30, n. 1, p.139-152, 2005.
MACDOUGAL, J.M.; FEUILLET, C. Systematics.. In: ULMER, T.; MACDOUGAL, J.M. (Ed.). Passiflora: passionflowers of the world. Portland: Timber Press, 2004. p 27-31.

MAPA - Instruções para execução dos ensaios de distinguibilidade, homogeneidade e estabilidade de cultivares de Passiflora. 2008. Disponível em: $<$ http:/www.agricultura.gov.br $>$. Acesso em: 10 jan. 2013.

MARIM, B. G.; JOSÉ, D.; CRESCÊNCIO, P.; CARNEIRO, S. Variabilidade genética e importância relativa de caracteres em acessos de germoplasma de tomateiro. Pesquisa Agropecuária Brasileira, Brasília,v. 44, n.1, p1.283-1290, 2009.

MELETTI, L.M.M. Avanços na cultura do maracujá no Brasil. Revista Brasileira de Fruticultura, Jaboticabal, v. 33, n.1, p.83-91, 2011.

MUSCHNER, V.C.; LORENZ, A.P.; CERVI, A.C.; BONATTO, S.L.; SOUZA-CHIES, T.T.; SALZANO, F.M.; FREITAS, L.B. First molecular phylogenetic analysis of passiflora (PASSIFLORACEAE). American Jornal of Botany, Columbus, v.90, p.1229-1238, 2003.

MUSCHNER, V.C.; ZAMBERLAN, P.M.; BONATTO, S.L.; FREITAS, L.B. Phylogeny, biogeography and divergence times in Passiflora (Passifloraceae). Genetics and Molecular Biology, Sao Paulo, v.35, p.1036-1043, 2012.

PIRES, A.A.; MONNERAT, P.H.; MARCIANO, C.R.; PINHO, L.G.R.; ZAMPIROLLI, P.D.; ROSA, R.C.C.; MUNIZ, R.A. Efeito da adubação alternativa do maracujazeiro-amarelo nas características químicas e físicas do solo. Revista Brasileira de Ciência do Solo, Viçosa, MG, v. 32, n. 5, p.19972005, 2008.

RONCATTO, G.; OLIVEIRA, J. C.; RUGGIERO, C.; NOGUEIRA FILHO, G. C.; APARECIDA, M.P.; CENTURION, C. Comportamento de maracujazeiros (Passiflora spp.) quanto à morte prematura. Revista Brasileira de Fruticultura, Jaboticabal, v.26, n.3, p. 552-554, 2004. 
SANTOS, E. A.; SOUZA, M. M.; VIANA, A P.; ALMEIDA, A. A. F.; FREITAS, J. C. O.; LAWINSCKY, P. R. Multivariate analysis of morphological characteristics of two species of passion flower with ornamental potential and of hybrids between them. Genetics and Molecular Research, São Paulo, v.10, p. 2457-2.471, 2011.

SAS INSTITUTE. SAS language and procedures: usage. Version SAS 9.1.3. Cary, 2003.

SOUZA, M. M.; PEREIRA, T. N. S.; CARNEIRO, M. L. Cytogenetic Studies in Some Species of Passiflora L . (Passifloraceae): A Review Emphasizing Brazilian Species, Brazilian Archives of Biology and Technology, Curitiba, v.5, n.2, p. 247-258, 2008.
SUDRÉ, C.P.; GONÇALVES, L.S.A.; RODRIGUES, R.; AMARAL JÚNIOR, A.T.; RIVA-SOUZA, E.M.; BENTO, C.S. Genetic variability in domesticated Capsicum spp as assessed by morphological and agronomic data in mixed statistical analysis. Genetics and Molecular Biology, São Paulo, v. 9, n.1, p.283-294, 2010.

TANGARIFE, M.M.M.; CAETANO, C.M.; TIQUE, C.A.P. Caracterización morfológica de especies del género Passiflora de Colombia. Acta Agronómica, Palmira, v.58, n.3, p.117-125, 2009.

VIANA, A.J.C.; SOUZA, M.M.; ARAÚJO, I.S.; CORREAA, R.X. Genetic diversity in Passiflora species determined by morphological and molecular characteristics. Biologia Plantarum, Praha, v.54, n. 3, p. $535-538,2010$. 